\title{
Obesity prevention in children and young people: what policy actions are needed?
}

\author{
William Bellewa,b, Adrian Baumanª, James Kitea, Bridget Foleyª, Lindsey \\ Reece $^{a}$, Margaret Thomas ${ }^{a}$, Seema Mihrshahia and Lesley Kinga \\ a Prevention Research Collaboration, Sydney School of Public Health, University of Sydney, NSW, Australia \\ b Corresponding author: william.bellew@sydney.edu.au
}

\section{Article history}

Publication date: March 2019

Citation: Bellew W, Bauman A, Kite J,

Foley B, Reece L, Thomas M, Mihrshahi S,

King L. Obesity prevention in children and young people: what policy actions are needed? Public Health Res

Pract. 2019;29(1):e2911902.

https://doi.org/10.17061/phrp2911902

\section{Key points}

- Overweight and obesity in childhood and adolescence are associated with adverse health consequences throughout life

- Population estimates for body mass index (BMI) among children and adolescents have begun to plateau at very high levels in many high-income countries, while still accelerating in parts of Asia

- Evidence based, cost-effective strategies are known but as yet not implemented fully in any country

- The most cost-effective strategies are those most vigorously opposed by industry

- Comprehensive policy actions must integrate transparent governance and accountability mechanisms for success

\section{Abstract}

Overweight and obesity in childhood and adolescence are associated with adverse health consequences throughout the lifecourse. Rates of childhood overweight and obesity have reached alarming proportions in many countries and pose an urgent and serious challenge. Policy responses across the world have been piecemeal. Evidence based policy actions and interventions are available to build a comprehensive approach to overweight and obesity but, in most countries, a narrow selection of interventions are chosen, often implemented over short time periods and typically with small-scale investment. The most cost-effective policy actions are rarely selected, or only partially adopted. Genuinely comprehensive, long-term population-wide approaches are scant. Leading-edge fiscal and regulatory strategies face aggressive, often effective, opposition from lobby groups. We outline the policy actions, governance and accountability mechanisms needed to tackle this global epidemic.

\section{Introduction}

Overweight and obesity carry profound health and economic burdens; as body mass index (BMI) increases throughout the life course, so does the prevalence of comorbid conditions, including diabetes, cardiovascular disease and some cancers. ${ }^{1}$ More immediate adverse health outcomes of childhood obesity include social and mental health concerns during adolescence. $^{2}$

Children and adolescents who are obese are five times more likely to be obese in adulthood than those who were not obese, representing a lifelong personal burden and long-term societal impacts. Around $55 \%$ of children who are obese will be obese in adolescence, around $80 \%$ of adolescents who are obese will still be obese in young adulthood, and around $70 \%$ will be obese over age $30 .{ }^{3}$ In 2016, among 5-19-year-olds, 50 million girls and 74 million boys worldwide were estimated to be obese, with an additional 213 million children and adolescents in the overweight category. ${ }^{4}$

Conversely, the majority of adults who are obese were not obese in childhood or adolescence, so early prevention will only partially reduce the prevalence of adult obesity. Adulthood is where much of the associated 
morbidity and healthcare cost burden occurs ${ }^{3}$; indeed, a lifelong approach was recommended in the Foresight report $^{5}$ - a UK Government analysis which brought together system-mapping and scenario-development methodologies to generate policy response options to obesity. Expert commentary has also revisited this lifecourse theme. ${ }^{6}$

Nonetheless, action to prevent and reduce overweight and obesity in childhood and adolescence, to reduce both societal and personal burdens, is undoubtedly needed, and likely has more immediate public and political appeal than dealing with adult obesity.
Policy makers can also consider the universal policy actions that are relevant for children but which would also confer benefits later in the life course, such as fiscal strategies and limitations on unhealthy product marketing.

\section{Policy actions to address obesity}

Evidence reviews from reputable independent organisations, represented selectively in Figure 1, are consistent in their recommendations on policy actions and interventions to address overweight and obesity among children and adolescents. 7,8 The reviews are

Figure 1. Categories of policy action, scale-up level and selected evidence based recommendations for policy actions to address overweight and obesity in children and adolescents

\section{Categories of policy action}

Amplifier policy actions are key to shifting the system and population as a whole but cannot act if the other elements are not in place

Enabler policy actions are ineffective alone but underpin the effectiveness of other policy actions (necessary but insufficient)

Focused policy actions are aimed directly at high-risk groups or individuals

\begin{tabular}{|c|c|}
\hline $\begin{array}{c}\text { Amplifier } \\
\text { policy actions }\end{array}$ & \multirow{3}{*}{$\begin{array}{l}\text { Recommended policy } \\
\text { actions } \\
\text { a Implement an effective tax on } \\
\text { sugar-sweetened beverages } \\
>\text { Implement the WHO set of } \\
\text { recommendations on the } \\
\text { marketing of foods and } \\
\text { nonalcoholic beverages }\end{array}$} \\
\hline SCALE-UP LEVEL 4 & \\
\hline $\begin{array}{l}\text { Population scale } \\
\text { (life course) }\end{array}$ & \\
\hline $\begin{array}{c}\text { Enabler } \\
\text { policy actions }\end{array}$ & \multirow{3}{*}{$\begin{array}{l}\text { Implement interpretive front } \\
\text { pack labelling, supported b } \\
\text { public education } \\
>\text { Implement targeted public } \\
\text { education campaigns on } \\
\text { physical activity }\end{array}$} \\
\hline SCALE-UP LEVEL 3 & \\
\hline Population scale & \\
\hline $\begin{array}{c}\text { (life stage) } \\
\text { SCALE-UP LEVEL } 2\end{array}$ & \multirow{2}{*}{$\begin{array}{l}\text { Require settings such as } \\
\text { schools, child care, sports } \\
\text { facilities and events to create } \\
\text { healthy food environments } \\
\text { Set standards for quality } \\
\text { physical education in schools }\end{array}$} \\
\hline $\begin{array}{l}\text { Setting scale } \\
\text { (systems design/ } \\
\text { setting logic) }\end{array}$ & \\
\hline $\begin{array}{l}\text { Focused } \\
\text { policy actions } \\
\text { ScALE-UP LEVEL1 }\end{array}$ & $\begin{array}{l}\text { Family-based, multicomponent } \\
\text { weight management services for } \\
\text { children and young people who } \\
\text { are obese }\end{array}$ \\
\hline
\end{tabular}

Subsetting scale

(program approach/

program logic)

$$
\begin{gathered}
\text { Scale-up } \\
\text { (potential population impact) } \\
\text { Levels } 1-4
\end{gathered}
$$


clear that no single action alone will suffice; scaled-up, comprehensive, multisectoral strategies are needed. The necessary suite of policies is described in the NOURISHING framework and food policy package for healthy diets and the prevention of obesity and diet-related noncommunicable diseases ${ }^{9}$, and in the INFORMAS framework. ${ }^{10}$ The NOURISHING framework comprises three broad categories of policies designed for: 1) food environments; 2) food systems; and

3) behaviour change communication. ${ }^{9}$ Although the noted policy actions are important and necessary to address obesity, policy action (especially fiscal policy) to reduce consumption of sugar-sweetened beverages has been suggested as the single most cost-effective intervention with respect to childhood obesity. ${ }^{11}$ Reducing marketing of energy-dense nutrient-poor foods to children has also been deemed highly cost-effective. ${ }^{7,11}$ We focus on these policy areas in particular in this paper. Fiscal strategies to reduce consumption of sugar-sweetened beverages and regulation of the marketing of unhealthy food and beverages feature prominently in the NOURISHING and INFORMAS policy frameworks, as well as in recent World Health Organization (WHO) recommendations. ${ }^{12}$

Despite consistent recommendations, the prominence of evidence based taxes and regulatory policy at the $\mathrm{WHO}$ and supranational level is reduced at country level to focus more on individual responsibility for childhood obesity prevention. 2,4 The NOURISHING framework database shows that some progress has been made in the fiscal domain with 34 countries having some form of tax on sugar-sweetened beverages by October 2018 ${ }^{13}$; however, researchers have also noted the challenges faced in several countries such as the US, Denmark, South Africa and Fiji. ${ }^{14}$ By contrast, mandatory regulation of broadcast food advertising to children is in place in only 10 countries. ${ }^{13}$

Reluctance to embrace fiscal and regulatory policy may be partly attributable to extensive corporate political activity by the food and beverage industries. Certain industry tactics have been shown to potentially influence national or regional public health-related policies and programs to favour business interests at the expense of public health. ${ }^{15}$ The reluctance to implement policy may occur even in the presence of a groundswell of community advocacy, indicating the power of industry influence. ${ }^{16}$ Internal contradictions are evident when policy makers' language of 'crisis' is used to describe the epidemic of childhood obesity, but not accompanied by commensurate policy action to address it. ${ }^{2}$ Our discussion of the limitations in fiscal and regulatory policy should not be taken to mean that other strategies are being well implemented; the verdict of 'patchy progress on obesity prevention' has been recorded by researchers ${ }^{17}$ and can now be verified in close to real time by examining the NOURISHING database. ${ }^{13}$

\section{Strategic governance and accountability}

The apparent ease with which industry lobby groups manage to advance their causes at the expense of public health ${ }^{18}$ highlights the need for policy to encompass not only the actions and interventions directed at the population but also the broader governance, coordination and accountability mechanisms needed to protect the public interest. These mechanisms were clearly elucidated in the Foresight report, which sets out two instructive checklists: 1) 14 criteria for an effective obesity strategy (pp 133-5); and 2) 10 criteria for successful management and coordination of the strategy by government (pp 138-9), which we have summarised in Figure 2. ${ }^{5}$ These criteria for effective policy actions and for effective policy governance, coordination and accountability were arguably embedded in the approach used for England's (£372 million over 3 years) crossgovernment strategy to tackle obesity - Healthy Weight, Healthy Lives (HWHL), except that a senior bureaucrat committee replaced the Cabinet-level committee stipulated in Foresight. ${ }^{19}$ Subsequent analysis of the development and implementation of HWHL stressed the importance of adequate funding and of the clear governance structure. In our view, the analysis serves to validate the Foresight criteria, at least in the English context. ${ }^{20}$ The need for these mechanisms is reinforced by recent research, yet they appear to be neglected by most national governments. ${ }^{21}$

\section{Discussion}

Notwithstanding the progress noted by others in this issue of the journal ${ }^{22,23}$, our assessment is that the requisite comprehensive policy actions and accountability mechanisms have yet to be implemented fully in any single country. ${ }^{17}$ We suggest four categories to examine such strategic error or failure: 1) shortcomings in strategy design; 2) investment failures; 3) inconsistent governance and accountability; and 4) underestimating the need for government intervention to address market failures.

\section{Shortcomings in strategy design}

Strategy design failure may arise through overreliance on too narrow a selection of actions or through implementation of less impactful, small-scale actions. An example of this is implementing popular educational and informational approaches - designed to target the knowledge and attitudes of individuals and thereby help them make 'informed choices' - but, critically, neglecting the powerful environmental and commercial determinants of obesity. ${ }^{17,24}$ Expecting secondary school-based physical activity programs to shift BMI and solve the obesity epidemic, 
Figure 2. Criteria for effective policy actions targeting obesity, and for effective policy governance, coordination and accountability

\begin{tabular}{l}
\hline Criteria for effective policy actions targeting obesity \\
\hline Investment for effectiveness of scaled-up policy actions \\
\hline Linkage with other policies for synergistic impacts \\
\hline Whole-of-life-course approach to policy implementation \\
\hline Monitoring and mitigation of unintended effects \\
\hline Government leadership and coordination across sectors \\
\hline Broad set of system levers \\
\hline Policy action at multiple levels \\
\hline Enabling (indirect) as well as focused policy actions \\
\hline Systematic, ongoing surveillance and risk analysis \\
\hline Mix of universal and targeted policy actions \\
\hline Both short- and long-term performance measures \\
\hline Independent evaluation, continuous improvement \\
\hline Broad engagement of strategy stakeholders \\
\hline Balance of cost-effective and sustainable policy actions \\
\hline
\end{tabular}

Note: Adapted from the Foresight report ${ }^{5}$ and work by Swinburn et al. ${ }^{21}$

and declaring them a failure when they inevitably achieve neither of these unrealistic goals, also falls into this category, doing a disservice both to obesity prevention and to the many other health and educational benefits of such physical activity programs. Education settings do have a potentially important strategic role in obesity prevention, given correct program specification and as part of a comprehensive portfolio. ${ }^{7}$

\section{Investment failures}

Investment failure arises when the necessary 'dose' (intensity and duration of actions) and comprehensiveness of the policy mix ('upstream' as well as 'downstream', universal as well as targeted, multisectoral and multisetting) are not achieved. Investment failure can occur if policies are:

- Unbalanced: overemphasis on less effective strategies, and/or

- Lightweight: omission of the most effective strategies, and/or

- Short term/spread thinly: insufficient resourcing for the necessary intensity and duration across the chosen policy mix.

Current understanding of the investment thresholds for strategies to attain population impact is imperfect, but this is often challenging in multistrategy complex interventions. Policy makers can make use of evidence
Criteria for effective policy governance, coordination and accountability

Incorporation of strategic advice from expert advisors

Partnership with multiple stakeholders inside and outside government

Robust surveillance and evaluation mechanisms

Comprehensive, high-level, long-term strategy

Cabinet-level support for government leadership

Allocation of sufficient resources

Long-term vision and goals as well as interim measures

Coordination within and outside government to synergise cross-cutting policies and link with local government

Utilisation of evidence and building on best practice

Transparency and accountability for use of public funds; stewardship to protect health from conflicts of interest

to guide investment, where it exists ${ }^{25}$, while ensuring evaluation mechanisms are in place to improve knowledge where evidentiary guidance is weak.

\section{Inconsistent governance and accountability}

Inconsistency in governance and accountability can arise in a variety of ways ${ }^{5,21}$, including:

- Lack of transparency

- Noninclusion of civil society

- Naïveté about industry lobbying and failure to address conflict of interest with the public good

- Not having Office of Prime Minister/Cabinet-level support and coordination for cross-government policy

- Under-involvement of independent technical experts

- Not committing to a culture of continuous improvement

- Lack of coordination and organisation to ensure: 1) continuous monitoring of implementation; 2) regular strategic review of the scope and duration of components within an overall plan; and 3) synthesis of implementation monitoring data, strategic review status, new evidence and modelling to inform and guide policy decisions within an iterative systemsbased approach. 


\section{Underestimation of the need for governments to address market failures}

Market failures have three main causes - market power, asymmetric information and externalities; the latter two are most relevant here. ${ }^{26,27}$ The current market heavily favours short-term behavioural preferences (overconsumption/underactivity) over long-term preferences (healthy consumption/active living). In an environment where unhealthy marketing is a ubiquitous backdrop to daily life (asymmetric information), expecting adults, let alone children, to make food and activity choices in their own best long-term interests is likely to be ineffective. Externalities (additional impacts) involve the social costs and benefits of certain forms of consumption not being fully reflected in their private costs and benefits to individual consumers ${ }^{26}$ - the cost of sugar-sweetened beverages may not fully reflect adverse societal impacts from their excessive consumption. Significant government reappraisal is required to correct such market failure. ${ }^{27}$ Government intervention to establish accessible physical activity infrastructure for walking, cycling and play, and especially to curtail unhealthy marketing that affects children, is vital. Without it, remaining obesity policy actions are diminished ${ }^{7,21,27,28}$, fail to tackle commercial determinants of health ${ }^{24}$, and are unlikely to reduce childhood obesity.

\section{Conclusions}

Despite progress, recommended policy actions have not been substantially implemented to tackle an epidemic that needs comprehensive, intensive and sustained efforts. It is necessary but insufficient for governments to select from the menu of obesity policy actions recommended by $\mathrm{WHO}$ and independent scientific syntheses. Success requires not only a comprehensive suite of policy actions but also the integration of mechanisms to prevent four types of strategic failure: 1) shortcomings in strategy design; 2) investment failure;

3) inconsistent governance and accountability; and 4) underestimating the robust government intervention needed to address market failure.

\section{Acknowledgements}

The evidence review by Bauman et al. was funded by the NSW Ministry of Health, brokered by the Sax Institute.

\section{Peer review and provenance}

Externally peer reviewed, commissioned.

\section{Competing interests}

The Prevention Research Collaboration is contracted by the NSW Ministry of Health to provide strategic advice and evaluation for physical activity, nutrition and obesity prevention programs.

\section{Author contributions}

WB, $A B$ and LK were responsible overall for the design, drafting and editing of the manuscript. JK, BF, MT and SM provided specialist advice, and reviewed and edited the manuscript. LR made additional edits. All coauthors commented on the edits and approved the final manuscript.

\section{References}

1. Guh DP, Zhang W, Bansback N, Amarsi Z, Birmingham $\mathrm{CL}$, Anis $\mathrm{AH}$. The incidence of co-morbidities related to obesity and overweight: a systematic review and meta-analysis. BMC Public Health. 2009;9:88.

2. Black N, Hughes R, Jones AM. The health care costs of childhood obesity in Australia: an instrumental variables approach. Econ Hum Biol. 2018;31:1-13.

3. Simmonds M, Llewellyn A, Owen CG, Woolacott N. Predicting adult obesity from childhood obesity: a systematic review and meta-analysis. Obes Rev. 2016;17(2):95-107.

4. NCD Risk Factor Collaboration. Worldwide trends in body-mass index, underweight, overweight, and obesity from 1975 to 2016: a pooled analysis of 2416 populationbased measurement studies in 128.9 million children, adolescents, and adults. Lancet. 2017;390(10113):2627-42.

5. Butland B, Jebb S, Kopelman P, McPherson K, Thomas S, Mardell J, Parry V. Foresight. Tackling obesities: future choices - project report (2nd Edition). London, UK: Government Office for Science; 2007 [cited 2019 Jan 24]. Available from: www.gov.uk/government/ uploads/system/uploads/attachment_data/file/287937/071184x-tackling-obesities-future-choices-report.pdf

6. Leeder S. Two roads converge in a yellow wood. Canberra: Public Health Association of Australia; 2018 [cited 2019 Jan 24]. Available from: www.phaa.net.au/ documents/item/2649

7. Bauman A, Bellew B, Boylan S, Crane M, Foley B, Gill T, et al. Obesity prevention in children and young people aged 0-18 years: a rapid evidence review brokered by the Sax Institute. Sydney: University of Sydney; 2016 [cited 2019 Jan 24]. Available from: tinyurl.com/y735oxza 
8. World Health Organization. Consideration of the evidence on childhood obesity for the Commission on Ending Childhood Obesity: report of the ad hoc working group on science and evidence for ending childhood obesity. Geneva: WHO; 2016 [cited 2019 Feb 5]. Available from: apps.who.int/iris/ bitstream/10665/206549/1/9789241565332_eng.pdf

9. Hawkes C, Jewell J, Allen K. A food policy package for healthy diets and the prevention of obesity and dietrelated non-communicable diseases: the NOURISHING framework. Obes Rev. 2013;14(S2):159-68.

10. Swinburn B, Sacks G, Vandevijvere S, Kumanyika S, Lobstein T, Neal B, et al. INFORMAS (International Network for Food and Obesity/non-communicable diseases Research, Monitoring and Action Support): overview and key principles. Obes Rev. 2013;14(S1):1-12.

11. Gortmaker SL, Wang YC, Long MW, Giles CM, Ward ZJ, Barrett JL, et al. Three interventions that reduce childhood obesity are projected to save more than they cost to implement. Health Aff (Millwood). 2015;34(11):1932-9.

12. World Health Organization. Report of the commission on ending childhood obesity. Implementation plan: executive summary. Geneva: WHO; 2017 [cited 2019 Feb 5]. Available from: apps.who.int/iris/bitstream/ handle/10665/259349/WHO-NMH-PND-ECHO-17.1-eng. pdf? sequence $=1 \&$ isAllowed $=\mathrm{y}$

13. World Cancer Research Fund International. London: World Cancer Research Fund. NOURISHING Database; 2018 [cited 2019 Feb 5]. Available from: www.wcrf.org/ int/policy/nourishing-database

14. Thow AM, Downs SM, Mayes C, Trevena H, Waqanivalu T, Cawley J. Fiscal policy to improve diets and prevent noncommunicable diseases: from recommendations to action. Bull World Health Organ. 2018;96(3):201-10.

15. Mialon M, Swinburn B, Allender S, Sacks G. 'Maximising shareholder value': a detailed insight into the corporate political activity of the Australian food industry. Aust N Z J Public Health. 2017;41(2):165-71.

16. Sundborn G, Thornley S, Beaglehole R, Bezzant N. Policy brief: a sugary drink tax for New Zealand and 10,000 -strong petition snubbed by minister of health and national government. N Z Med J. 2017;130(1462):114-6.

17. Roberto CA, Swinburn B, Hawkes C, Huang TT, Costa SA, Ashe M, et al. Patchy progress on obesity prevention: emerging examples, entrenched barriers, and new thinking. Lancet. 2015;385(9985):2400-9.
18. Han E. Beverages industry praises itself for turning politicians away from sugar tax. Sydney Morning Herald; 2017 Oct 22 [cited 2019 Feb 7]. Available from: www. smh.com.au/healthcare/beverages-industry-praises-itselffor-turning-politicians-away-from-sugar-tax-20171020gz520t.html

19. Jebb SA, Aveyard PN, Hawkes C. The evolution of policy and actions to tackle obesity in England. Obes Rev. 2013;14(S2):42-59.

20. Hawkes C, Ahern AL, Jebb SA. A stakeholder analysis of the perceived outcomes of developing and implementing England's obesity strategy 2008-2011. BMC Public Health. 2014;14:441.

21. Swinburn B, Kraak V, Rutter H, Vandevijvere S, Lobstein T, Sacks G, et al. Strengthening of accountability systems to create healthy food environments and reduce global obesity. Lancet. 2015;385(9986):2534-45.

22. Rissel C, Innes-Hughes C, Thomas M, Wolfenden L. Reflections on the NSW Healthy Children Initiative: a comprehensive, state-delivered childhood obesity prevention initiative. Public Health Res Pract. 2019;29(1):e2911908.

23. Love P, Laws R, Hesketh KD, Campbell KJ. Lessons on early childhood obesity prevention interventions from the Victorian Infant Program. Public Health Res Pract. 2019;29(1):e2911904

24. Kickbusch I, Allen L, Franz C. The commercial determinants of health. Lancet Glob Health. 2016;4(12):e895-e6.

25. Wiggers J, Wolfenden L, Campbell E, Gillham K, Bell C, Sutherland R, et al. Good for kids, good for life, 20062010: evaluation report. Sydney: NSW Ministry of Health; 2013 [cited 2019 Feb 5]. Available from: www.health.nsw. gov.au/research/Publications/good-for-kids.pdf

26. Karnani A, McFerran B, Mukhopadhyay A. The obesity crisis as market failure: an analysis of systemic causes and corrective mechanisms. Journal of the Association for Consumer Research. 2016;1(3):445-70.

27. Moodie R, Swinburn B, Richardson J, Somaini B. Childhood obesity - a sign of commercial success, but a market failure. Int J Pediatr Obes. 2006;1(3):133-8.

28. Vallgårda S. Childhood obesity policies - mighty concerns, meek reactions. Obes Rev. 2018;19(3):295-301.

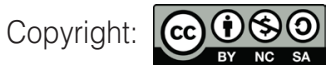

(C) 2019 Bellew et al. This article is licensed under the Creative Commons Attribution-NonCommercial-ShareAlike 4.0 International Licence, which allows others to redistribute, adapt and share this work non-commercially provided they attribute the work and any adapted version of it is distributed under the same Creative Commons licence terms. See: www.creativecommons.org/licenses/by-nc-sa/4.0/ 